\title{
Opinião
}

\section{DISCUTINDO O CONCEITO DE AUTOCONHECIMENTO COM ALUNOS DE CIÊNCIAS SOCIAIS}

Gislene Farias de Oliveira (1)

José Felipe de Lima Alves (2)

\begin{abstract}
Resumo
O autoconhecimento sempre representou uma busca constante e incessante entre os estudiosos, pois trata-se de um assunto por demais subjetivo, que está relacionado a um objeto em constante mudança que é o homem. $\mathrm{O}$ Curso de Ciências Sociais da Universidade Regional do Cariri, tem dentre suas propostas curriculares, o desenvolvimento de habilidades interpessoais, tais como a empatia, a solidariedade e o respeito mútuo. O presente estudo aborda a aplicação de metodologia vivencial no ensino das Ciências Sociais, mais especificamente, para trabalhar o conceito de autoconhecimento. Dessa forma foi conduzida uma atividade em sala com alunos da disciplina de Psicologia Social do $3^{a}$ semestre. A experiência constou basicamente de um relaxamento breve para facilitar a visualização, ao final do qual, foram orientados a responderem a seguinte pergunta: "eu me sinto como se fosse...", através da técnica do desenho livre. Ao final, foi discutido o sentimento e o aprendizado evocado pela experiência da expressão metafórica de si mesmos. Os resultados apareceram de forma contrastante, evocando tanto sentimentos positivos de possibilidade e segurança, como sentimentos negativos, experienciados na forma de incerteza. Concluímos pois, que a metodologia vivencial proporcionou aos estudantes um aprendizado em termos de autoconhecimento e conhecimento sobre a vida, possibilitadores de reflexões para uma vida melhor.
\end{abstract}

Palavras-Chave: Metodologia; Vivência; Autoconhecimento

\section{Introdução}

Os conceitos de autoconhecimento, auto-estima e liberdade são ferramentas que podem ser utilizadas na melhoria da qualidade de vida do ser humano, e os profissionais de Ciências Sociais, tanto quanto Psicólogos e Pedagogos podem fazer uso delas. Seja qual for a área de atuação, o profissional está sempre trabalhando com outros indivíduos. No caso mais específico do curso de Ciências Sociais, é imprescindível o autoconhecimento para que se possa agir da melhor forma com os outros, sempre atento para ser o menos coercitivo possível. Este comportamento, certamente criará melhores condições para proporcionar autoconhecimento, conhecimento do outro e, em muitos casos melhorar a auto-estima das pessoas sob sua responsabilidade.

Segundo Skinner (1993), o caminho para a consciência passa pela autoconsciência. Já Matos (1995), nos orienta que a palavra consciência remete à idéia de uma instância psíquica, um self decisor, enquanto comportamento consciente.

Outros autores como Weber (2003), acreditam que estar consciente é o mesmo que poder autodescrever-se, isto é, ter a capacidade de relatar os próprios comportamentos num dado momento. Skinner 
(1982) acreditava que, quanto mais consciente, mais sensível ao ambiente, e mais aumentada a capacidade de discriminar e descrever comportamentos próprios.

$\mathrm{O}$ autoconhecimento e a conseqüente autoconsciência, são importantes recursos para aqueles que desejam melhorar seus relacionamentos e sua qualidade de vida, principalmente no ambiente laboral.

A saúde emocional dos profissionais parece ainda ser uma temática latente nos dias de hoje. Características como desrespeito, inabilidade no trato interpessoal, desconfiança, insegurança, tem sido habitualmente apontadas como fatores responsáveis ou desencadeantes de dificuldades emocionais e comprometimento do Bem-estar.

O uso da metodologia vivencial em sala de aula reforça positivamente a experiência de aprendizado, dando origem a um aprendizado mais significativo e duradouro. Além disso, a metodologia vivencial tem sua justificativa em proporcionar uma constante e rápida mudança que é indispensável para desenvolver a capacidade dos alunos, em termos de: flexibilidade; auto-conhecimento, empatia; respeito; gerenciamento da mudança e da incerteza; trabalho de equipe para atingir objetivos comuns; perseverança; assunção de riscos calculados e necessidade de planejamento (OLIVEIRA e CALLOU, 2006).

Segundo Carvalho Neto e Melo (2004), a metodologia vivencial deve ser utilizada nas situações em que esse instrumento didático tenha um claro objetivo de aprendizado. No nosso caso, na explicitação prática dos conceitos de autoconhecimento.

\section{Método}

O estudo foi organizado a partir do material coletado numa atividade vivencial proposta para 30 (trinta) alunos de ambos os sexos, sendo 21 feminino e 9 masculinos, com idades variando de 19 a 27 anos, da disciplina de Psicologia Social do $3^{\mathrm{a}}$ semestre do curso de Ciências Sociais da Universidade Regional do Cariri, no município de Crato-CE, em junho de 2011. Nessa experiência, foram trabalhados os conceitos de autoconhecimento e autoconsciência.

Durante o procedimento, os alunos foram estimulados a um breve relaxamento, através da concentração corporal e em seguida a descreverem a si mesmos através de um desenho livre, respondendo a seguinte pergunta: "Eu me sinto como se fosse...". Em seguida os alunos agruparam-se aos pares com a finalidade de compartilhar com os colegas as impressões eliciadas na experiência.

Eles foram orientados a iniciarem o diálogo à partir do desenho, expressando suas percepções de si. Puderam compartilhar sentimentos e relatar o que aprenderam. Estas observações foram acrescentadas ao desenho, em forma de relato.

A seguir descreve-se os resultados dos relatos dos participantes.

\section{Resultados}

Com relação ao Reconhecimento de si, pelos participantes, a experiência parece ter eliciado duas categorias contrastantes: Uma Positiva, evocando sentimentos de Possibilidade e de Segurança para consigo 
mesmo. Neste caso, a visão de si denotou uma elevada auto-estima dos participantes. E, uma Negativa, onde os alunos se perceberam como pessoas inseguras ante suas próprias possibilidades.

A seguir, apresenta-se as descrições das categorias evocadas na experiência.

Descrições das Categorias e Subcategorias das percepções experienciadas pelos participantes, a partir da representação de si mesmos, obtidos dos relatos. As questões-estímulo foram: Eu me sinto como se fosse(...) $\boldsymbol{e}$, Meu sentimento agora (...).

A experiência fez emergir nos alunos duas categorias. Um grupo se reconheceu de maneira positiva, percebendo em si Possibilidade e Segurança. Outro grupo se reconheceu de uma forma mais negativa, evocando uma percepção de Incerteza, como pode ser observado pelas falas dos participantes, a seguir.

CATEGORIA 1 - POSITIVA, com duas sub-categorias:

a) Possibilidade. Neste caso, os alunos se reconheceram como um ser pleno de possibilidades. Essa subcategoria ficou demonstrada através das seguintes falas: "brilho melhor”, "sou importante”, “existirei e brilharei”, "sou infinito”, “inteligente”, "maleável”, “exploradora”, "confiável”, “em busca da felicidade”, "tranqüila”, "feliz”, “apaixonada”, "posso dar bons frutos”.

b) Segurança. Neste caso, suas Representações de si mesmos denotaram tranqüilidade e segurança. Observe-se suas falas: “confortável”, "livre” (2), "satisfeito”, “eu mesma em erros e acertos”, "várias belezas", " liberdade”, "sabedoria/ternura/amor", "uma flor entre as outras em um jardim".

CATEGORIA 2 - NEGATIVA, com uma sub-categoria:

a) Incerteza. Neste caso, os alunos se reconheceram como pessoas com limitação, dúvida e temor em relação a sua capacidade pessoal, frente a certas situações. Essa subcategoria ficou demonstrada através das seguintes falas: “dividido", "observada”, "uma folha ao vento”, “indeciso” (2), “dois caminhos que preciso escolher", "tempestade”, "bem/mal”, incomodada”, "nem grande nem pequena", ridícula", "perdida”, preguiçosa”, "triste”, "agitada”, "cheia de informações e confusa”, "nada de diferente, na mesma”, "misteriosa”, “às vezes calmo e às vezes agitado”.

Com relação ao questionamento aos participantes sobre “O que aprendi com a vivência?”, observou-se duas categorias. Alguns participantes sentiram que a vivência promoveu uma maior consciência de si mesmos (Autoconhecimento), outros puderam experienciar um fortalecimento quanto a uma maior compreensão sobre a vida ( Conhecimento sobre a vida), como pode ser observado nas falas a seguir:

CATEGORIA 1 - Autoconhecimento: Neste caso, a vivência parece ter sido promotora de uma profunda reflexão sobre si mesmos. A saber: "gosto mais de ouvir do que de falar”; "quando me observam fico incomodada”; “continuarei a ser o que sou”; "sou independente possuindo várias belezas e sendo infinito”"sou passível de mudança e aberto para várias construções sociais”; “ devo ser livre e me desprender de influências”; "que sou querida, má desenhista e tagarela... para mim está tudo bem”; “ sou abstrata... maleável 
e reclusa...”;" eu persisto na idéia de segurança de mim mesmo”" quando me acomodo fico bastante sonolenta”; “ que preciso o quanto antes decidir por mim mesma, o que realmente importa para mim”; “ reforçou o conceito que tinha sobre conhecimento de si mesmo, me fez crescer”; "minhas emoções são manifestadas de acordo com o tempo"; “ que minhas atitudes tem que ser tomadas pela lógica”; "basta aprender, ter calma e tudo se resolve”; "eu preciso escolher o que é melhor para mim”; “ posso me realizar com as coisas mais simples que estão a minha volta”; " tenho muito a descobrir"; "tenho que trabalhar a minha interdependência” “ aprendi sobre autoconhecimento e autoconceito”.

CATEGORIA 2- Conhecimento sobre a vida: A vivência foi experienciada como um recurso pessoal que permite viver melhor. A saber pelas frases eliciadas: "que o mal se sobressai acima do bem”; "que o certo pode ser errado" "que é necessário ser livre para expressar pensamentos e emoções “ que é necessário ter autonomia e disposição para ocupar seu próprio espaço”; "que o importante é ser feliz”; “ que é necessário escolher aquilo que é mais importante”; “ tenho que reconhecer no outro que ele é necessário, para que eu possa ser feliz”; “que compreender o outro nas suas diferenças, que incomoda não nele, mas em mim”; "é preciso escolher o que é melhor para mim” "que a vida é bela”; “ quando a gente reflete sobre a vida, conseguimos compreender o que queremos...".

\section{Discussão}

Este tipo de metodologia, em cursos das Ciências Sociais, parece promover um maior contato dos alunos com situações que suscitam reflexão acerca de seus sentimentos, atitudes e comportamentos. Os resultados corroboram observações de Martins (1995) que afirma que, se os profissionais das Ciências Humanas tiverem uma mente aberta, não saturada por preconceitos, estarão diante de uma riqueza de conhecimentos imensa ao seu alcance.

Oliveira e Callou (2006), realizaram um estudo com 40 (quarenta) alunos do segundo semestre de medicina da Universidade Federal do Ceará - Barbalha em 2005, na disciplina de Psicologia do desenvolvimento, onde foi introduzida uma nova metodologia conhecida como Trabalho colaborativo, na educação médica. Esta modalidade de atividade permitiu aos participantes se auto-ajudarem no seu processo de aprendizagem, atuando como parceiros entre si, visando adquirir um determinado conhecimento. As autoras concluíram que este tipo de trabalho além de promover o acesso dos alunos a novas tecnologias aplicadas na educação médica, também proporcionou o desenvolvimento de habilidades inter-pessoais, necessárias a outras situações da vida pessoal e profissional.

Giffoni et. al. (2007), em estudo semelhante acerca das representações sociais sobre o uso de uma metodologia vivencial no tratamento de pessoas com dificuldades mentais e emocionais e seus familiares, concluiu que esta evocou nos participantes representações positivas acerca da metodologia, relacionadas ao Bem-estar, a Socialização e a Ressignificação, possibilitando um novo modo de pensar suas atitudes e comportamentos. A autora concluiu que a adoção de uma metodologia vivencial, ajudou os participantes a se reconhecerem como sujeitos ativos do seu processo de mudança. 
Observa-se neste caso a semelhança relacionada às evocações positivas de Possibilidade e Segurança, onde a vivência parece ter sido promotora de uma nova consciência a respeito do seu autoconhecimento, do conhecimento do outro e de um melhor conhecimento sobre a vida.

\section{Conclusão}

A atividade proposta aos alunos trabalhou os conceitos de autoconhecimento e autoconsciência, exigindo concentração, respeito aos colegas, gestão do tempo e empatia. Estes são recursos necessários ao gerenciamento de problemas individuais e de relacionamento, seja nas atividades cotidianas laborativas ou na vida. Portanto, a utilização de metodologia vivencial no curso de Ciências Sociais, parece ter se mostrado útil, na medida em que proporcionou um maior contato com sentimentos próprios e dos colegas, o que possibilitou uma maior conscientização de suas atitudes e percepção de si mesmos, promotoras do autoconhecimento.

\section{Referências}

CARVAlho NETO, C. Z. \& MELO, M. T. E agora, professor? Por uma Pedagogia Vivencial. IFCE Instituto para a Formação Continuada em Educação (edição em Multimídia): São Paulo, 2004

GIFFONI, F.A.O.; OLIVEIRA, G.F.; BRANCO, L.C.C e NOGUEIRA, R.R. S. A Terapia comunitária como metodologia inovadora no tratamento do desconforto emocional. Trabalho apresentado no V Forum Nacioanl de Metodologias Ativas de Ensino-Aprendizagem. Londrina-PR. Agosto, 2007.

MATOS, M. A. (1995). Behaviorismo metodológico e behaviorismo radical. Em B. Range (Org.). Psicoterapia comportamental e cognitiva: pesquisa, prática, aplicações e problemas (pp. 27-34). Campinas: Psy.

OLIVEIRA, G F.e CALLOU, D.T. A Introdução do Trabalho Colaborativo na Educação Médica. Trabalho apresentado no XXI Outubro Médico. Fortaleza-CE. Outubro, 2006

SKINNER, B. F. (1982). Sobre o behaviorismo. São Paulo: Cultrix.

SKINNER, B. F. (1993). Ciência e comportamento humano. São Paulo: Martins Fontes.

WEBER, L. N. D (2003). Skinner: um homem além de seu tempo. Em P. I. C. Gomide \& L. N. D. Weber. Análise experimental do comportamento: manual de laboratório. 6a ed. (pp. 129-149). Curitiba: Ed. da UFPR.

Sobre os autores:

(1) Gislene Farias de Oliveira é Psicóloga, Doutora em Psicologia Social e Professora da Universidade Federal do Ceará. E-mail: gislenefarias2011@ @otmail.com

(2) José Felipe de Lima Alves é acadêmico de Ciências Sociais pela Universidade Regional do Cariri Crato/CE. E-mail: Felipe.alves.2@hotmail.com 


\section{Como citar este artigo (Formato ISO):}

OLIVEIRA, G.F.; ALVES, J.F L. Discutindo o conceito de autoconhecimento com alunos de Ciências Sociais. Id on Line Revista de Psicologia, Novembro de 2011, vol.1, n.15, p.12-17. ISSN 1981-1189. 